\title{
Nuevas (y no tan nuevas) aproximaciones a la historia de la vida cotidiana
}

\section{New (and Not so New) Approaches to the History of Everyday Life}

Alfredo Ruiz IsLAS

Departamento de Historia-Universidad Iberoamericana.

México

Correo:aruizislas@gmail.com

https://orcid.org/0000-0002-6285-5595

DOI 10.48102/hyg.vi55.331

Artículo recibido: $\mathrm{I}_{\mathrm{I}} / \mathrm{O}_{3} / 2020$

Artículo aceptado: 31/03/2020

Gonzalbo Aizpuru, Pilar. Hablando de historia. Lo cotidiano, las costumbres, la cultura, México, El Colegio de México-Centro de Estudios Históricos, 2019. (La aventura de la vida cotidiana. Historia-teoría y método, 7).

En enero de 20 I 8 tuvo lugar, en El Colegio de México, el coloquio Hacia una Nueva Historia de la Vida Cotidiana. En Donde Todos Tenemos Algo que Decir, organizado por el Seminario de Historia de la Vida Cotidiana que la misma institución alberga. Al encuentro concurrió una veintena de estudiosos de la cotidianidad: algunos, los más, habituales del seminario -y de sus publicaciones-; otros, los menos, participantes esporádicos en las actividades del grupo, estudiosos del pasado cuyos trabajos pueden, con cierta facilidad, englobarse en la temática general del seminario. Las conferencias dictadas, repartidas en seis mesas, terminaron por integrarse en un volumen más de los que, desde hace tres décadas, edita el seminario; ${ }^{1}$ a la par, Pilar Gon-

${ }^{1}$ Pilar Gonzalbo Aizpuru (ed.), La historia y lo cotidiano, México, El Colegio de México-Centro de Estudios Históricos-Seminario de Historia de la Vida Cotidiana, 20I9.

Historia y Grafia, Universidad Iberoamericana, año 28, núm. 55, julio-diciembre 2020, pp. I67-I72 
zalbo -cabeza del grupo desde sus primeros momentos de existencia y coordinadora del coloquio- decidió tomar nota de las preguntas formuladas por los asistentes, agregar las que, regularmente, llegaban a ella vía correo electrónico y redes sociales, y dar respuesta a todas a través de un libro donde, de paso, le permitiera presentar los conceptos que, en términos generales, rigen su quehacer historiográfico. El resultado de sus afanes es Hablando de historia. Lo cotidiano, las costumbres, la historia, al que se dedican estas breves líneas.

Gonzalbo parte de un par de preguntas simples, con base en las cuales organiza los contenidos de su texto: 1) ¿cómo hacer frente a las mil y una vicisitudes que aparecen al estudiarse la vida cotidiana desde una perspectiva histórica?; 2) ¿cómo hacer, entonces, la historia de la vida cotidiana? Son preguntas metodológicas. Preguntas que sitúan al estudioso, desde el primer momento, frente a frente con las aristas prácticas de su quehacer, con las dificultades propias de delimitar un problema de investigación en tiempo y espacio, establecer un conjunto de sujetos a estudiar, definir un corpus de fuentes en particular e idear un modo plausible de escribir lo que resulte de la pesquisa. Entender que el libro tiene un fundamento metodológico resulta de interés en varios sentidos. Primero, porque impide pensarlo como un texto de carácter teórico - uno que estaría organizado en torno a preguntas como "qué es la historia de la vida cotidiana", o quizá "cómo puede pensarse la historia de la vida cotidiana"- y, por ende, evita formularle preguntas en este mismo sentido. Segundo, porque deja ver con claridad el porqué de sus contenidos, sus alcances e incluso la poética que lo rige. Tercero, porque da pie para inscribirlo en la órbita del texto redactado por la misma autora hace algunos ańos, ${ }^{2}$ lo que permite ver en qué áreas su pensamiento se ha transformado, en cuáles permanece más o menos estático y en qué otras los cambios han sido más bien marginales.

La obra se divide en ocho capítulos. Tres de ellos -los primeros- abordan cuestiones relacionadas con la conformación de la

${ }^{2}$ Pilar Gonzalbo, Introducción al estudio de la vida cotidiana, México, El Colegio de México-Centro de Estudios Históricos, 2006. 
representación histórica y los alcances de la interpretación; el papel del lenguaje en la construcción del conocimiento histórico y la importancia que la perspectiva conceptual asumida por el estudioso del pasado tiene en el tipo de preguntas que se realice $-\mathrm{y}$, por supuesto, en las explicaciones que construya a partir de ellas; finalmente, los alcances y los límites de las fuentes históricas y la relación que guardan éstas con la objetividad. Aun cuando, en principio, podría parecer que esta tercia de capítulos se dedica a abordar, de forma más o menos profunda, asuntos de corte teórico, lo cierto es que la argumentación termina por recalar en los ya mencionados terrenos de la metodología, del quehacer concreto, del ejemplo que ilustra, pero que queda atrapado en sí mismo. No sobra decir que esta misma preeminencia del método sobre otros asuntos determina que los grandes conceptos que estarían ligados a la temática general de la obra -historia, vida cotidiana, historia de la vida cotidiana, incluso historia cultural, campo al que la autora remite sus afanes- sean abordados en apenas unas pocas líneas, lo que suscita algunos problemas, dado que deja en el vacío y el sobreentendido lo que, para una cabal comprensión del texto, debiera ser explicado con cierta profundidad.

El lado metodológico de la obra se ve con claridad en el resto de los capítulos que la integran. Todos, sin excepción, poseen una estructura similar, en la que la revisión de los asuntos amplios y complejos es seguida por la exposición de las materias concretas que la práctica historiográfica ha englobado, con el paso del tiempo, en la historia de la vida cotidiana. De esta forma, el cuarto capítulo de la obra aborda la conformación de lo íntimo y lo privado y la relación de ambas instancias con la cotidianidad, para de ahí reflexionar sobre los distintos modos en los que es posible historizar los sentimientos en general y los miedos en particular. En tanto, el quinto capítulo habla de lo cotidiano como una expresión de la cultura y a continuación ubica, dentro de esa misma cultura, manifestaciones como los modales, el lujo o el vestido. Por su parte, el sexto capítulo expone la condición cotidiana de lo público y lo lleva a la esfera de los medios, las prácticas religiosas e, incluso, el conflicto y la violencia. El séptimo capítulo, a su vez, se refiere a lo doméstico, lo que tiene lugar 
dentro de los muros de la casa, lo que se relaciona con la familia y los diferentes modos de aproximarse a su estudio desde la perspectiva de la vida cotidiana. Para cerrar, el octavo capítulo estudia las relaciones entre la cultura, lo popular, el folclor y lo cotidiano, lo que faculta a la autora para hablar, a vuelapluma, lo mismo de la cultura de masas que de los medios y la tecnología o del lenguaje popular y la identidad.

La organización dada a los contenidos de la obra le permite a la autora hilvanar explicaciones de manera ágil, sencilla, con buen lenguaje, a fin de que su ulterior lector tome nota de los obstáculos que aparecen en el camino de cualquiera que se decida a estudiar la cotidianidad y tenga herramientas para deshacerse de ellos. El tono de los argumentos es íntimo, personal, como si se tratara de una charla amistosa sostenida en un café, lo que con toda probabilidad contribuirá a la buena recepción de lo que la autora sostiene por parte de un lector no particularmente avezado en la materia, sino al que, más bien, se asume como novato en esas lides. Ahora bien, el asunto a dilucidar reside en cómo se consigue esta familiaridad, esta cercanía, esta llaneza del lenguaje que será el vehículo ideal para la transmisión del conocimiento. La respuesta es simple: hablando siempre en primera persona, desde la experiencia propia, desde lo que el trabajo paciente y constante le ha enseñado a Gonzalbo acerca del quehacer historiográfico en general y de la construcción de historias de la vida cotidiana en particular. Más allá de los conceptos, o incluso los ejemplos, que pudieran proporcionar las fuentes indicadas en el aparato crítico de la obra -sucinto, incluso exiguo, aunque preciso-, lo que comunica el texto es aquello que la autora sabe, aquello en lo que cree; aquello que, a lo largo de los años, ha extraído de la madeja informe del saber y ha separado luego de encontrarlo correcto, útil y adecuado.

A partir de lo mencionado, resulta de interés preguntarse con quién dialoga Pilar Gonzalbo a lo largo de los capítulos que dan forma a su libro, si es que tal cosa -el diálogo con un sujeto ausente, presente sólo a través de la palabra que ha quedado establecida en el texto y que puede entenderse, e interpretarse, de muy distintas 
formas- es posible. $\mathrm{O}$, para decirlo de otra forma, con quién es que, historiográficamente, discute las cuestiones centrales de su texto, los asuntos que constituyen lo cotidiano, los métodos susceptibles de emplearse para el estudio de la historia, las posibilidades que brindan los vestigios del pasado de los que es posible echar mano. A simple vista parecería que esos interlocutores, esos individuos a los que por igual interpela o de quienes toma ideas que permitan apoyar sus argumentos, son los que se encuentran consignados en las notas a pie de página, donde desfilan nombres de peso y prosapia como Foucault, Elias, Heller, Chartier o Benjamin, entre varios más. Eso parecería obvio y, además, le conferiría a la obra una solidez considerable; sin embargo, al leer con detenimiento el texto y, sobre todo, al analizar por dónde se mueven los argumentos de Gonzalbo -o sea, las respuestas a las preguntas que le han sido formuladas en diferentes contextos-, sale a la luz el hecho de que no existe tal interlocutor. $\mathrm{O}$, más bien, existe, pero no es quien podría pensarse en primera instancia. El aparato crítico cumple con su función retórica habitual de convencer al lector de que, más allá del escrito, existe un argumento probado y autorizado que legitima lo que ahí se ha expuesto. No obstante, lo que de modo formal aportan los contenidos de las notas a pie de página es escaso: se trata sólo de títulos y autores poseedores de un peso incuestionable, pero que no terminan de conectarse con las ideas vertidas en el texto por la simple razón de que no funcionan como fuente de explicaciones de cualquier clase -sean amplias y profundas o incluso elementales-, sino únicamente como un conjunto de nombres a los que el lector dota de significado e integra a su lectura en la medida en que le dicen algo y lo remiten a un supuesto o una idea, pero no porque ese supuesto o esa idea resuenen en lo mostrado por Gonzalbo. Ellos, entonces, no son los entes con los que dialoga la autora, no son con quienes discute, no son el referente, el punto de arranque o el objeto de la discusión. Por ende, es posible afirmar, sin demasiadas complicaciones, que la interlocutora, la persona con la que dialoga Pilar Gonzalbo, es ella misma, con base en su configuración como autoridad y en el peso específico que ha adquirido dentro del campo de estudio en el que se mueve. 
Al observar el modo en el que la autora se remite a los libros que ha editado -con el concurso de los participantes del Seminario de Historia de la Vida Cotidiana- y, en particular, a los temas que ha abordado, a las preguntas que se han realizado, a las fuentes que ha consultado y a los procedimientos que ha empleado para dar salida a todo ello y convertirlo en explicaciones históricas, es perceptible que todo está organizado de forma tal que parecería que sus posiciones historiográficas no han variado a lo largo del tiempo. En este sentido, se trata de un diálogo que es todo congruencia, todo armonía, todo diafanidad. No hay asperezas en él, no hay contradicciones, no hay virajes bruscos o siquiera cambios de rumbo sutiles: cualquier texto del pasado permite dar respuesta a las preguntas que, en el presente, se hace la autora, o le hace alguien más, porque las ideas son las mismas. Como si el diálogo no tuviera lugar de forma diacrónica -lo que implicaría la existencia de diferencias entre el pasado y el presente- y, en lugar de ello, se estableciera en lo sincrónico, donde no hay ninguna dificultad al momento de considerar las ideas expresadas en textos más o menos antiguos porque, al fin y al cabo, son las mismas que se defienden en el presente. Este proceder dota de congruencia a la explicación y le resta asperezas quizá innecesarias, dado que elimina la necesidad de explicar las transformaciones sufridas por el propio pensamiento a lo largo del tiempo. Sin embargo, son precisamente estas explicaciones las que el lector interesado en la materia estaría esperando, más aún si se trata, como se comentó en su oportunidad, de alguien que se inicia en las lides del quehacer historiográfico y quiere saber -necesita saber- cómo es que se construyen los conceptos desde los que trabaja el historiador, qué es lo que puede llegar a modificarlos, qué implicaciones tiene -en el corto y el mediano plazos- esta alteración de lo que se piensa en relación con el pasado y con el modo en el que se encara ese pasado. Cómo es, en suma, que se verifica el tránsito intelectual de alguien que, si bien centra sus esfuerzos en la dilucidación de un conjunto más o menos específico de problemas históricos, no tiene, en todo momento, la misma perspectiva en relación con eso a lo que se enfrenta. 霆 